\title{
Role of Liver in Alzheimer's Disease
}

\author{
Swatilekha Roy Sarkar ${ }^{1}$, Rajib Dutta ${ }^{2 *}$ \\ ${ }^{I} M D S$, Consultant Orthodontist, India \\ ${ }^{2} \mathrm{MD}$, Consultant Neurology, India \\ *Corresponding Author: Rajib Dutta, MD, Consultant Neurology, India, Email: rajibdutta@163.com

\begin{abstract}
Dementia is a major problem presently of high-income countries and also an increasing concern of low-income nations worldwide. Alzheimer's disease (AD) is the most common progressive neurodegenerative dementing disorder. It is clinically characterized by a preclinical stage, followed by mild cognitive impairment (MCI) due to the progression of the disease into AD dementia. The earliest symptoms of AD include memory problems, disorientation in time and space, and difficulty with calculation, language, concentration and judgment. As the disease evolves, patients may develop severe behavioral abnormalities and may even become psychotic. In the late stages, the sufferers are incapable of self-care and become bedbound, for years or even decades. It is characterized by the accumulation of amyloid $\beta$ in the form of extracellular plaques and by intracellular neurofibrillary tangles. Genetic data, autopsy and neuroimaging studies in $A D$ patients show A $\beta$ plaque deposition precedes cortical tau pathology. Peripheral organs like liver, kidney play important roles in the clearance of brain-derived A . In this review article we will discuss about the role of liver in pathogenesis of $A D$.
\end{abstract}

Keywords: Alzheimer's disease, liver function test, taupathology, metabolic dysfunction.

\section{INTRODUCTION}

Alzheimer's disease (AD) is a neurodegenerative disease characterized by the accumulation of extra cellular amyloid $\beta$ in the form of plaques and the intracellular accumulation of hyperphosphorylated tau proteins as neurofibrillary tangles (NFT), with progressive neuronal loss and cerebral atrophy [1]. The amyloid- cascade hypothesis introduced in 1991 provides an explanation of the pathogenesis of AD [2]. AD typically affects memory initially, but atypical presentations can occur, particularly in younger patients [3]. AD eventually progresses to involve diffuse cortical functions, lead into the inability to manage basic day to day activities. AD also causes a number of psychological and behavioral changes which can cause significant distress to patients, care givers and a big health care burden $[4,5]$

Based on Alzheimer's Disease International Federation (ADI), at least 46.8 million people are affected by dementia worldwide, that anticipated to be 74.7 million by 2030 and 131.5 million by 2050[6]. This disease can be categorized in two forms: early-onset familial Alzheimer disease (EFAD) [7] and Late-onset Alzheimer's disease (LOAD) or non-familial [8]. EFAD is dominantly inherited but LOAD form is rathera complex or multi factorial disease [9]. The pathogenesis of $\mathrm{AD}$ is very complex, though genetic [10] and neuropathological [11], studies suggest that elevations of amyloid $\beta$ play a central role. However, target interventions intended to prevent amyloid $\beta$ accumulation did not demonstrate clinical efficacy in preventing or slowing the disease despite having biomarker evidence [12, 13]. Preclinical evidence from AD animal model and patient-derived human induced $\mathrm{A} \beta$ pluripotent stem cell model indicates that tau pathology can progress independent of accumulation of amyloid $\beta$, genetic risk factors and other aberrant metabolic pathways [14].

The foundation of amyloid hypothesis was the discovery of autosomal dominant mutations in three genes namely APP, PSEN1 and PSEN2 (the latter two encoding presenilin1 and 2, respectively), that cause pathogenic aggregation of $\mathrm{A} \beta$ peptides into neuritic plaques $[15,16]$. Although mutations in APP, PSEN1 and PSEN2 do not occur in sporadic AD, similar neuropathological changes in $A \beta$ and tau are observed in both familial and sporadic AD [1720]. Researchers believe pathogenesis of $\mathrm{AD}$ includes other mechanisms like microgliosis, 
immuneoreactivity, oxidative stress and dysregulation of protein homeostasis [2, 21]

Role of liver as a peripheral organ in pathogenesis of $\mathrm{AD}$ is not much studied. Peripheral organs are responsible for the clearance of about $40 \%$ of brain-derived $\mathrm{A} \beta$ in APP/PS1 mice [22]. Wang et al has reported previously that shifting the action site from the center to periphery might be safer for the clearance of brain $A \beta$ as it may decrease the inflammatory process in the brain [23]. It is a well known fact that kidney participates in the peripheral clearance of brain-derived $\mathrm{A} \beta$ [24, 25]. Liver is also an important metabolic organ in periphery, and the role of liver in peripheral $\mathrm{A} \beta$ metabolism is being studied extensively now. Indirect evidences in the past has shown that cirrhosis patients had significantly higher plasma levels of $A \beta$ and inflammatory factors as compared to healthy adults and plasma $A \beta$ levels were positively correlated with the hepatic functions [26].

Liver is the main peripheral organ responsible for lipid metabolism. Increasing evidence suggests that abnormal lipid metabolism is associated with increased risk for $\mathrm{AD}$ [27]. It is reported that $A \beta$ binds to $A p o E$ and maybe chaperoned in transport with cholesterol from the brainas a means of toxin clearance [28]. Low-density lipoprotein (LDL) receptor-related protein 1 (LRP1) and its ligand, ApoE, are genetically associated with $\mathrm{AD}$ and plasma $\mathrm{A} \beta$ levels [29]. LRP1 is suggested to facilitate $A \beta$ clearance from the brain across the blood-brain barrier (BBB) [30]. Moreover, it is demonstrated that enhancing the expression of LRP1 in liver aids in peripheral clearance of $A \beta$ [31]. Insulin is suggested to facilitate the liver mediated peripheral clearance of $A \beta$ by intracellular translocation of LRP1 to the plasma membrane in hepatocytes [32]. Once efflux from the brain, $A \beta$ is transported to the liver by high-density lipoprotein (HDL) particles [33]. However there is no direct evidence regarding the role of liver in peripheral $A \beta$ clearance. It is indicated that a large amount of $A \beta$ in the blood binds to serum albumin [34].

Patients with Alzheimer disease (AD) display metabolicdys function [35]. Clinical studies suggest that impaired signaling, energy metabolism, inflammation, and insulin resistance play a role in $\mathrm{AD}[36,37]$. Metabolic disorders (eg, diabetes, hypertension, obesity, and dyslipidemia) are risk factors for $\mathrm{AD}$ and contribute to cortical thinning [38]. Alanine amino transferase (ALT) and As part ate amino transferase (AST) are used in general clinical practice to measure liver injury $[39,40]$ and are factors associated with metabolic diseases [41] known risk factors of $\mathrm{AD}$ and cognitive decline [42]. Many researchers think amino transferases are surrogate biomarkers of liver metabolic functioning. Decreased levels of ALT and elevated AST: ALT ratio was observed in patients with $\mathrm{AD}$ with poor cognition and reduced brain glucose metabolism. Increased AST: ALT ratio was associated with lower CSF amyloid- $\beta$ 1-42 levels, greater amyloid- $\beta$ deposition, and higher CSF p-tau and t-taulevels. Furthermore, it was also observed that decreased levels of ALT were associated with greater amyloid- $\beta$ deposition and structural atrophy [43]. Altered liver enzymes lead to disturbances in liver-associated metabolites including branchedchain amino acids, ether phosphatidylcholines, and lipids which are altered in AD and may play a role in disease pathophysiologic characteristics [44].

\section{DISCUSSION}

Disturbed energy metabolism is one of the processes that may explain the observed lower levels of ALT and increased enzyme ratio in individuals with $\mathrm{AD}$ and impaired cognition [37]. Brain glucose hypo metabolism is an early feature of $\mathrm{AD}$ and cognitive impairment during the prodromal stage [45]. ALT and AST are key enzymes in gluconeogenesis in the liver and production of neurotransmitters required in maintaining synapses [46]. Possible mechanisms may explain altered levels of enzymes in AD. First, reduced ALT levels lead to reduced pyruvate, which is required for glucose production via gluconeogenesis in the liver and glucose is distributed in various body tissues as an energy source [47], thus disturbing energy homeostasis. Second, altered levels of ALT and AST may affect levels of glutamate, an excitatory neurotransmitter of the central nervous system involved in synaptic transmission, which also plays an important role in memory [48].

In the case of low glucose metabolism in the brainless $\alpha$-ketoglutarate is available via the tri carboxylic acid cycle that favors glutamate catabolism vs glutamate synthesis in reversible reaction (catalyzed by AST and ALT) [49]. Glutamate acts as a neurotransmitter in approximately two-thirds of the synapses in 
neocortical and hippocampalpyramidal neurons and thus is involved in memory and cognition via long-term potentiation [50]. Plasma ALT and AST levels were significantly positively correlated with plasma glutamate levels [40]. In older adults, lower serum ALT levels are associated with mortality [51]. Alanine amino transferase decreases with age [52] and may be a sign of hepatic aging. Glutamate levels also decrease with increasing age [53]. Together with the fact that age is the strongest risk factor for AD [54], decreasing levels of ALT with age may also indicate a possible biological link between aging and $\mathrm{AD}$.

Increased AST to ALT ratios are observed in individuals with nonalcoholic fatty liver disease, which is the hepatic manifestation of metabolic syndrome [55]. In the Framingham Heart Study, non-alcoholic fatty liver disease was associated with smaller total cerebral brain volume even after adjustment for multiple cardiovascular risk factors [56]. Liver dysfunction is also associated with the development of disease including cardiovascular disease and insulin resistance through disruptions in glucose and lipid metabolism [57, 58]. Increased alkaline phosphates levels in individuals with $\mathrm{AD}$ and an inverse association with cognition [59]. The neuronal form of alkaline phosphatase plays a role in developmental plasticity and activitydependent cortical functions via contributing in $\gamma$-aminobutyric acid metabolism [60], however changes in plasma levels of alkaline phosphatase may occur as a result of central nervous system injury [61].

\section{CONCLUSION}

Liver plays an important role in peripheral metabolism of amyloid $\beta$ causing efflux from brain to periphery. Altered liver function markers are associated with $\mathrm{AD}$ diagnosis and impaired memory and executive function as well as amyloid- $\beta$, tau, and neurodegenerative biomarkers of AD pathophysiological characteristics. The causal pathways are not clear yet. More studies are needed to understand the liver brain axis in longitudinal and model systems in future for complete understanding and gaining deeper knowledge of the pathways.

\section{ACKNOWLEDGEMENT}

The authors have no relevant affiliations or financial involvement with any organization or entity with a financial interest in or financial conflict with the subject matter or materials discussed in the manuscript. Special thanks to my supervisor Professor Dr. Huifang Shang who gave initial ideas and supported me through this research study. I would also like to thank Dr. Swatilekha Roy Sarkar for her valuable feedback on the manuscript and literature screening from PubMed.

\section{REFERENCES}

[1] Scheltens P, Blennow K, Breteler MMB, et al. Alzheimer's disease. Lancet 2016; 388:505-17. doi:10.1016/ S0140-6736(15)01124-1.

[2] Selkoe, D. J. \& Hardy, J. The amyloid hypothesis of Alzheimer's disease at 25 years. EMBO Mol. Med. 8, 595-608 (2016).

[3] Mendez MF. Early-onset Alzheimer disease and its variants. Continuum (MinneapMinn) 2019;25:34-51.

[4] Mega MS, Cummings JL, Fiorello T, Gornbein J. The spectrum of behavioral changes in Alzheimer's disease. Neurology 1996;46:130-5. doi:10.1212/WNL.46.1.130.

[5] Zhao QF, Tan L, Wang HF, et al. The prevalence of neuropsychiatric symptoms in Alzheimer's disease: systematic review and metaanalysis. J Affect Disord2016;190:264-71. doi:10.1016/j.jad.2015.09.069.

[6] Realdon O, Rossetto F, Nalin M, Baroni I, Cabinio M, Fioravanti R, et al. Technologyenhanced multi-domain at home continuum of care program with respect to usual care for people with cognitive impairment: the Ability TelerehABILITation study protocol for a randomized controlled trial. BMC Psychiatry 2016;16:425.

[7] Bird TD. Early-onset familial Alzheimer disease. 2012.

[8] Ozaki, K., and S. Niida. "Genetic Background for Alzheimer's Disease: Knowledge Accumula ted from AD GWAS." Brain and nerve= Shinkeikenkyu no shinpo 71.10 (2019): 10391051.

[9] Rhinn H, Fujita R, Qiang L, Cheng R, Lee JH, Abeliovich A. Integrative genomics identifies APOE $\varepsilon 4$ effectors in Alzheimer's disease. Nature 2013;500:45-50.

[10] Scheuner D, Eckman C, Jensen M, et al. Secreted amyloid betaprotein similar to that in the senile plaques of Alzheimer's disease is increased in vivo by the presenilin 1 and 2 and APP mutations linked to familial Alzheimer's disease. Nat Med 1996;2:864-70. doi:10.1038/ nm0896-864.

[11] Glenner GG, Wong CW. Alzheimer's disease: initial report of the purification and characterize ation of a novel cerebrovascular amyloid protein. 
BiochemBiophys Res Commun1 984; 120:88590.doi:10.1016/S00 06-291X(84) 8019 0-4.

[12] Boche D, Denham N, Holmes C, Nicoll JAR. Neuropathology after active Abeta42 immunothe rapy: implications for Alzheimer's disease pathogenesis. Acta Neuropathol2010; 120:36984. doi:10.1007/s004 01-010-0719-5.

[13] Sevigny J, Chiao $P$, Bussière $T$, et al. The antibody aducanumab reduces $A \beta$ plaques in Alzheimer's disease. Nature 2016;537:50-6. doi:10.1038/nature19323.

[14] Van der Kant, R., Goldstein, L. S. B., \&Ossenkoppele, R. (2019). Amyloid- $\beta$-indepen dent regulators of tau pathology in Alzheimer disease. Nature Reviews Neuroscience. doi:10. 1038/s41583-019-0240-3.

[15] Hardy, J. \&Allsop, D. Amyloid deposition as the central event in the aetiology of Alzheimer's disease. Trends Pharmacol. Sci. 12, 383-388 (1991).

[16] Selkoe, D. J. The molecular pathology of Alzheimer's disease. Neuron 6, 487-498 (1991).

[17] Ringman, J. M. et al. Neuropathology of autosomal dominant Alzheimer disease in the National Alzheimer Coordinating Center Database. J. Neuropathol. Exp. Neurol. 75, 28 4-290 (2016).

[18] [18] Gordon, B. A., Blazey, T. M., Christensen, J., Dincer, A., Flores, S., Keefe, S., ... Benzinger, T. L. S. (2019). Tau PET in autosomal dominant Alzheimer's disease: relationship with cognition, dementia and other biomarkers. Brain. doi:1 0.1093/brain/awz019.

[19] Quiroz, Y. T., Sperling, R. A., Norton, D. J., Baena, A., Arboleda-Velasquez, J. F., Cosio, D., Johnson, K. A. (2018). Association Between Amyloid and Tau Accumulation in Young Adults With Autosomal Dominant Alzheimer Disease. JAMA Neurology, 75(5), 548. doi:10. 1001/jamaneurol.2017.4907.

[20] Schöll, M., Ossenkoppele, R., Strandberg, O., Palmqvist, S., Jögi, J.Ohlsson, T. (2017). Distinct 18F-AV-1451 tau PET retention patterns in early- and late-onset Alzheimer's disease. Brain, 140(9), 2286-2294. doi:10.109 3/brain/awx171.

[21] De Strooper, B., \&Karran, E. (2016). The Cellular Phase of Alzheimer's disease. Cell, 164(4),603-615.doi:10.1016/j.cell.2015.12.056.

[22] Xiang Y, Bu XL, Liu YH, Zhu C, Shen LL, Jiao SS, Zhu XY, Giunta B et al (2015) Physiological amyloid-beta clearance in the periphery and its therapeutic potential for Alzheimer's disease. Acta Neuropathol 130 (4):487-499.doi:10.1007/s00401-015-1477 - 1.

[23] Liu YH, Wang YR, Xiang Y, Zhou HD, Giunta B, Manucat-Tan NB, Tan J, Zhou XF et al (2015) Clearance of amyloid-beta in Alzheimer's disease: shifting the action site from center to periphery. Mol Neurobiol 51 (1): 1-7. doi:10.1007/s12035-014-8694-9.

[24] Liu YH, Xiang Y, Wang YR, Jiao SS, Wang $\mathrm{QH}, \mathrm{Bu}$ XL, Zhu C, Yao XQ et al (2015) Association between serum amyloid-beta and renal functions: implications for roles of kidney in amyloid-beta clearance. Mol Neurobiol 52 (1):115-119. doi:10.1007/s12035-014-8854-y.

[25] Kitaguchi N, Hasegawa M, Ito S, Kawaguchi K, Hiki Y, Nakai S, Suzuki N, Shimano Y et al (2015) A prospective study on blood Abeta levels and the cognitive function of patients with hemodialysis: a potential therapeutic strategy for Alzheimer's disease. J Neural Transm (Vienna) 122(11):1593-1607. doi:10. 1007/s00702-015-1431-3.

[26] Wang, Y.-R., Wang, Q.-H., Zhang, T., Liu, Y.H., Yao, X.-Q., Zeng, F. Wang, Y.-J. (2016). Associations Between Hepatic Functions and Plasma Amyloid-Beta Levels-Implications for the Capacity of Liver in Peripheral AmyloidBeta Clearance. Molecular Neurobiology, 54(3), 2338-2344. doi:10.1007 /s12035-016-9826-1.

[27] Lesser, G. T. (2012). Association of Alzheimer Disease Pathology with Abnormal Lipid Metabolism: The Hisayama Study. Neurology, 78(16), 1280-1280. doi:10.1212/wnl.0b013e3 $18254 \mathrm{f} 6 \mathrm{ad}$.

[28] Holtzman, D. M., Herz, J., \& Bu, G. (2012). Apolipoprotein $\mathrm{E}$ and Apolipoprotein $\mathrm{E}$ Receptors: Normal Biology and Roles in Alzheimer Disease. Cold Spring Harbor Perspectives in Medicine, 2(3), a006312a006312. doi:10.1101/cshperspect.a006312.

[29] Kang DE, Pietrzik CU, Baum L, Chevallier N, Merriam DE,Kounnas MZ, Wagner SL, Troncoso JC et al (2000) Modulation of amyloid beta-protein clearance and Alzheimer's disease susceptibility by the LDL receptor-related protein pathway. J Clin Invest 106(9):1159-1166. doi:10.1172/JCI11013.

[30] Sagare AP, Deane R, Zlokovic BV (2012) Low-density lipoprotein receptor-related protein 1: a physiological Abeta homeostatic mechanism with multiple therapeutic opportunities. PharmacolTher 136(1):94-105. doi:10.1016/j.pharmthera.2012.07.008.

[31] Sehgal N, Gupta A, Valli RK, Joshi SD, Mills JT, Hamel E, Khanna P, Jain SC et al (2012) Withaniasomnifera reverses Alzheimer's disease pathology by enhancing low-density lipoprotein receptor related protein in liver. Proc Natl Acad Sci U S A 109(9):3510-3515. doi:10.1073/pnas.1112209109.

[32] Tamaki C, Ohtsuki S, Terasaki T (2007) Insulin facilitates the hepatic clearance of plasma amyloid beta-peptide (1 40) by intracellular translocation of low-density lipoprotein receptorrelated protein 1 (LRP-1) to the plasma 
membrane in hepatocytes. MolPharmacol 72(4): 850-855. doi:10.1124/m ol.107. 036913.

[33] Hottman DA, Chernick D, Cheng S, Wang Z, Li L (2014) HDL and cognition in neurodegenerative disorders. Neurobiol Dis. 72 Pt A:22-36. doi: 10.1016/j.nbd.2014.07.015.

[34] Stanyon HF, Viles JH (2012) Human serum albumin can regulate amyloid-beta peptide fiber growth in the brain interstitium: implications for Alzheimer disease. J Biol Chem 287(3 3):28163-28168.doi:10.1074/jbc.C112.360 800 .

[35] Toledo JB, Arnold M, Kastenmüller G, et al; Alzheimer's disease Neuroimaging Initiative and the Alzheimer Disease Metabolomics Consortium. Metabolic network failures in Alzheimer's disease: a biochemical road map. Alzheimer's Dement. 2017;13(9):965-984. doi: 10.1016/j.jalz.2017.01.020.

[36] Clarke JR, Ribeiro FC, Frozza RL, De Felice FG, Lourenco MV.Metabolic dysfunction in Alzheimer's disease: from basic neurobiology to clinical approaches. J Alzheimers Dis. 201 8;64(s1):S405-S426.doi: 10.3233/JAD-179 911.

[37] Kapogiannis D, Mattson MP. Disrupted energy metabolism and neuronal circuit dysfunction in cognitive impairment and Alzheimer's disease. Lancet Neurol. 2011;10(2):187-198. doi:10.101 6/S1474-4422(10) 70277-5.

[38] Craft S. The role of metabolic disorders in Alzheimer disease and vascular dementia: two roads converged. Arch Neurol. 2009;66(3):300305. doi:10.1001/archneurol.2009.27.

[39] Sookoian S, Pirola CJ. Alanine and aspartate amino transferase and glutamine-cycling pathway: pathogenesis of metabolic syndrome. World J Gastroenterol. 2012;18 (29):3775-3781. doi:10.3748/wjg.v18. i29.3775.

[40] ]Sookoian S, Castaño GO, Scian R, et al. Serum aminotransferases in nonalcoholic fatty liver disease are a signature of liver metabolic perturbations at the amino acid and Krebs cycle level. Am J Clin Nutr. 2016;103(2):422-434. doi:10.3945/ajcn.115.118695.

[41] Sattar N, Scherbakova O, Ford I, et al;West of Scotland Coronary Prevention Study. Elevated alanine aminotransferase predicts new-onset type 2 diabetes independently of classical risk factors, metabolic syndrome, and C-reactive protein in theWest of Scotland Coronary Prevention Study. Diabetes. 2004;53(11):28552860. doi:10.2337/diabetes.53.11.2855.

[42] Santos CY, Snyder PJ,WuW-C, ZhangM, Echeverria A, Alber J. Pathophysiologic relationship between Alzheimer's disease, cerebrovascular disease, and cardiovascular risk: a review and synthesis. AlzheimersDement (Amst). 2017;7:69-87.

[43] Nho, K., Kueider-Paisley, A., Ahmad, S., MahmoudianDehkordi, S., Arnold, M., Risacher,
S. L. (2019). Association of Altered Liver Enzymes with Alzheimer Disease Diagnosis, Cognition, Neuroimaging Measures, and Cerebrospinal Fluid Biomarkers. JAMA Network Open, 2(7), e197978. doi:10.1001/jam anetworkopen.2019.7978.

[44] Pietzner M, Budde K, Homuth G, et al. Hepatic steatosis is associated with adverse molecular signatures in subjects without diabetes. J Clin Endocrinol Metab. 2018;103(10):3856-3868. doi:10.1210/jc.2018-00999.

[45] Mosconi L, Sorbi S, de Leon MJ, et al. Hypometabolism exceeds atrophy in presymp tomatic early-onset familial Alzheimer's disease. J Nucl Med. 2006;47 (11):1778-1786.

[46] Rui L. Energy metabolism in the liver. Compr Physiol. 2014;4(1):177-197. doi:10.1002/cphy c130024.

[47] Qian K, Zhong S, Xie K, Yu D, Yang R, Gong $\mathrm{D}-\mathrm{W}$. Hepatic ALT isoenzymes are elevated in gluconeogenic conditions including diabetes and suppressed by insulin at the protein level. DiabetesMetab Res Rev. 2015;31(6): 562-571. doi:10.1002/dmrr.2655.

[48] Reis HJ, Guatimosim C, PaquetM, et al. Neurotransmitters in the central nervous system \& their implication in learning and memory processes. Curr Med Chem. 2009;16(7):796840.doi:10.2174/092 986709787549271.

[49] FleckMW, Henze DA, Barrionuevo G, Palmer AM. Aspartate and glutamate mediate excitatory synaptic transmission in area CA1 of the hippocampus. J Neurosci. 1993;13(9):3944-3955. doi:10.1523/JNEUROS CI.13-09-03944. 1993.

[50] Francis PT. Glutamatergic systems in Alzheimer's disease. Int J Geriatr Psychiatry. 2003;18(suppl 1):S15-S21.doi:10.1002/gps 934.

[51] Liu Z, Ning H, Que S, Wang L, Qin X, Peng T. Complex association between alanine aminotransferase activity and mortality in general population: a systematic review and meta-analysis of prospective studies. PLoS One. 2014;9(3):e91410. doi:10.1371/journal.pone.00 91410.

[52] Elinav E, Ben-Dov IZ, Ackerman E, et al. Correlation between serum alanine amino transferase activity and age: an inverted $\mathrm{U}$ curve pattern. Am J Gastroenterol. 2005;100 (10):2201-2204. doi:10.1111/j.1572-0241.2005. 418 22.x.

[53] Kaiser LG, Schuff N, CashdollarN,WeinerMW. Age-related glutamate and glutamine concentra tion changes in normal human brain: $1 \mathrm{H}$ MR spectroscopy study at $4 \mathrm{~T}$. Neurobiol Aging. 2005;26(5):665-672. doi:10.1016/j. neurobiola ging.2004.07.001.

[54] Guerreiro R, Bras J. The age factor in Alzheimer's disease. Genome Med. 2015;7:106. doi:10.1186/s1307 3-015-0232-5. 
[55] Katsiki N, Perez-Martinez P, Anagnostis P, Mikhailidis DP, Karagiannis A. Is nonalcoholic fatty liver disease indeed the hepatic manifestation of metabolic syndrome? Curr Va scPharmacol. 2018;16(3):219-227. doi:10.2174/ 1570161115666170621075619.

[56] Weinstein G, Zelber-Sagi S, Preis SR, et al. Association of nonalcoholic fatty liver disease with lower brain volume in healthy middleaged adults in the Framingham Study. JAMA Neurol. 2018; 75 (1): 97-104. Doi:10.1001/ jamaneurol.2017.3229.

[57] Bedogni G, Gastaldelli A, Tiribelli C, et al. Relationship between glucose metabolism and non-alcoholic fatty liver disease severity in morbidly obese women. J Endocrinol Invest. 2014;37(8):739-744. doi:10.1007/s40618-0140101-x.

[58] Perla FM, Prelati M, Lavorato M, Visicchio D, Anania C. The role of lipid and lipoprotein metabolism in non-alcoholic fatty liver disease. Children (Basel). 2017;4(6):E46.

[59] Kellett KAB, Williams J, Vardy ER, Smith AD, Hooper NM. Plasma alkaline phosphatase is elevated in Alzheimer's disease and inversely correlates with cognitive function. Int $\mathrm{J}$ Mol Epidemiol Genet. 2011;2(2):114-121.

[60] Fonta C, Négyessy L, Renaud L, Barone P. Areal and subcellular localization of the ubiquitous alkaline phosphatase in the primate cerebral cortex: evidence for a role in neurotransmission. Cereb Cortex. 2004;14(6): 595-609. doi:10.1093/cercor/bhh021.

[61] Yamashita M, Sasaki M, Mii K, et al. Measurement of serum alkaline phosphatase isozyme I in brain-damaged patients. Neurol Med Chir (Tokyo). 1989;29(11):995-998. doi:10.2176/nmc.29.995.

Citation: Swatilekha Roy Sarkar, Rajib Dutta, Role of Liver in Alzheimer's Disease. ARC Journal of Neuroscience. 2019; 4(3):20-25. doi: dx.doi.org/10.20431/2456-057X 0403003.

Copyright: () 2019 Authors. This is an open-access article distributed under the terms of the Creative Commons Attribution License, which permits unrestricted use, distribution, and reproduction in any medium, provided the original author and source are credited. 